Research Article

\title{
Study of Allergic Rhinitis by using RAP Questionnaire and Skin Lesions in a Group of Shoe Factory Workers in India: A Cross-sectional Study
}

\author{
Anand Jain ${ }^{1}$, Priyanka Choudhary ${ }^{2}$, Ashiya Goel $^{3}$, Amit Kumar Mital $^{4}$, RB Jain $^{5}$, Rajat Gupta $^{6}$, \\ Vijay $^{7}$, Tarun Singh $^{8}$ \\ ${ }^{1}$ Senior Resident, Department of Medicine, Baba Saheb Ambedkar Medical College, New Delhi, India. \\ ${ }^{2}$ Senior Resident, ${ }^{5}$ Senior Professor and Head, ${ }^{6,7,8}$ Junior Resident, Department of Community Medicine, Pt BD Sharma PGIMS, \\ Rohtak, Haryana, India. \\ ${ }^{3}$ Senior Resident, Department of Otorhinolaryngology, Pt BD Sharma PGIMS, Rohtak, Haryana, India. \\ ${ }^{4}$ Assistant Professor, Department of Paediatrics, World College of Medical Sciences and Research and Hospital, Haryana, India. \\ DOI: https://doi.org/10.24321/2455.7048.202105
}

\section{I $\quad \mathbf{N} \quad \mathbf{F} \quad \mathbf{O}$}

\section{Corresponding Author:}

Amit Kumar Mital, World College of Medical Sciences and Research and Hospital, Jhajjar, Haryana, India.

E-mail Id:

mittal1.amit@gmail.com

Orcid Id:

http://orcid.org/0000-0002-5315-3663

How to cite this article:

Jain A, Choudhary P, Goel A, Mital AK, Jain RB, Gupta R, Vijay, Singh T. Study of Allergic Rhinitis by using RAP Questionnaire and Skin Lesions in a Group of Shoe Factory Workers in India: A Crosssectional Study. Epidem Int. 2021; 6(1): 22-27.

Date of Submission: 2021-03-06

Date of Acceptance: 2021-03-21

\section{$\begin{array}{llllllll}\mathbf{A} & \mathbf{B} & \mathbf{S} & \mathbf{T} & \mathbf{R} & \mathbf{A} & \mathbf{C} & \mathbf{T}\end{array}$}

Background: The footwear industry is a significant segment of leather industry in India. Workers in shoe industry are exposed to mixtures of organic solvents used for colouring, adhesion, cleaning and fumes which could lead to respiratory and skin problems.

Objectives: To study allergic rhinitis symptoms and examine skin lesions in workers exposed to harmful agents in footwear industry.

Methodology: It is a cross-sectional study conducted in November 2018 for 4 days among industrial workers in a selected factory of Footwear Park, developed by the Haryana State Industrial Development Corporation (HSIDC) of Bahadurgarh. RAP (Respiratory Allergy Prediction test) questionnaire for allergic rhinitis and questions on type and number of skin lesions were asked.

Result: 51 workers were selected for the study. Workers involved in printing and moulding responded positively to one or more than one questions of RAP questionnaire used for screening allergic rhinitis. $31.4 \%$ had itching, $27.5 \%$ had papules, $7.8 \%$ had blisters, $7.8 \%$ had oozing, and $15.7 \%$ had dry/ scaly skin. Itching, papules, blisters, oozing, and dry/ scaly skin were found only on the head/ neck, hands and arms/ forearms with no involvement of lower legs and trunk. Skin problems like itching and papules were significantly associated with printing and moulding of shoes $(\mathrm{p}<0.05)$.

Conclusion: Shoe-making involves exposure to many hazardous compounds and toxic fumes that may cause allergic rhinitis as well as skin allergies in the form of skin lesions especially those involved in printing and moulding of shoes.

Keywords: Shoe Factory Workers, Allergic Rhinitis, Skin Lesions, Rap Questionnaire 


\section{Introduction}

The footwear industry is a significant segment of the leather industry in India and is only second to the footwear industry of China. It is a labour intensive industry and is mainly based in small and cottage industry sectors. Workers in this industry are exposed to significant occupational health hazards leading to diseases that vary from minor irritations or injuries to cancers.

There are several processes involved in footwear making like measuring, last making, pattern cutting, sewing, assembling, and finishing. Each of these processes is associated with different types of health hazards due to frequent exposure to mixtures of organic solvents used for colouring, adhesion, and cleaning. The adhesive process was considered especially hazardous because of the extensive use of organic solvents and because a warming process is employed for the sole to adhere to the shoe. The workers are exposed to various chemicals such as p-tert butylphenols (used in neoprene adhesives), benzene (used as a solvent in glues), and leather dust. The continuous and long-lasting exposure to fumes and glues leads to skin infections and respiratory problems among the workers.

Acute poisoning of these adhesives may lead to respiratory and cardiovascular failure and death. The study by Zuskin et al., ${ }^{2}$ on footwear manufacturing workers showed that atmospheric pollution in the shoe industry may be responsible for the development of acute and chronic respiratory impairment. The severity of compromised lung function increased with the duration of employment. The study by Paggiaro et al., ${ }^{3}$ showed clinical and functional respiratory problems in workers of shoe factories exposed to organic solvents from glue or other adhesives.

In shoe production, there are many possible occupational exposures to a broad spectrum of allergens contained in many adhesives, dyes, acrylic resins, preservatives, rubber, leather, and many kinds of glues (neoprene, epoxy resin, and rubber glues).

The chemicals (solvents/ adhesives) used in shoe industry are highly irritant to the skin and in association with wet conditions, the risk of dermatitis and skin damage is increased. ${ }^{4,5} \mathrm{~A}$ study at 5 shoe manufacturers in Italy showed a prevalence of occupational contact dermatitis of $14.6 \%$, hyperkeratosis of fingertips in $6 \%$ and pruritus in $3.2 \%$ of the workers. ${ }^{6}$

Inhalation of these solvents (fumes/ gases) or the leather dust in workplaces where bottom soles are being treated causes irritation of the respiratory tract. Thus, workers suffer from respiratory problems, lung diseases and skin infections through constant exposure to fumes and irritants like glues and adhesive. Hence we intended to study the allergic and respiratory symptoms as well as examine the skin lesions in workers exposed to harmful agents in the footwear industry.

\section{Material and Method}

This was a cross-sectional study design. The study was conducted in the Footwear Park, developed by the Haryana State Industrial Development Corporation (HSIDC) in the industrial area of Bahadurgarh District of Haryana. Industrial workers of all age groups working in the selected factory were included in the study. The factory was visited in the month of November 2018 for 4 days when data was collected from the sample population.

Inclusion Criteria: Workers who had 8-10 years of experience in the shoe industry and those who were residing within the same locality with similar socio-economic conditions and cooking practices were included in the study.

Exclusion Criteria: Workers who had a previous history of respiratory problems (asthma, chronic bronchitis, and COPD), cardiac problems or a history of other diseases prior to their employment in the shoe industry, those who were habitual smokers and those who were not willing to participate in the study were excluded.

\section{Sampling Methodology}

There were 306 units in the Footwear Park of the industrial area of Bahadurgarh. 1 unit was selected based on feasibility and cooperation of the management system of the factory. The manufacturing of shoes consists of 5 sections: cutting and stitching, moulding, labelling and printing, packaging, and quality check. In the selected factory, about 300 workers were employed with 50-60 workers in each section of the manufacturing unit. 51 workers from different sections of the factory, fulfilling the inclusion criteria, were selected randomly and were interviewed in 4 days visit.

Consent: Prior permission from the management of the footwear industry was taken before conducting the study. Written informed consent from each of the study participants was also taken.

Study Tool: RAP (Respiratory Allergy Prediction test) questionnaire is a self-administered easy-to-use instrument in the primary care physician setting containing 9 questions, used to screen for allergic rhinitis. The tool was developed by Galimberti et al., in year $2015 .^{7}$ The results of the questionnaire prompted the physician for a speciality referral to the allergist. Responses from each worker were collected by the investigators themselves by interview technique. Questions related to the type and number of skin lesions and site of lesions were also recorded.

Statistical Analysis: The data were analysed using SPSS Version 20.0 (Statistical Package for Social Sciences) software. Descriptive data were analysed in form of percentages and for inferential statistics, chi-square test 
and Fisher exact test (if the value in any of the cells was less than 5 ) were used. The $p$ value of less than 0.05 was taken as significant.

\section{Results}

The study was conducted among 51 workers, out of which, $7(13.7 \%)$ were from packaging section, 4 (7.8\%) were from quality check section, 10 (19.6\%) were from printing section, and 30 (58.8\%) were from moulding section. The mean age of study participants was $26.56 \pm 1.21$ years with a maximum age of 53 years and a minimum age of 19 years. $78.4 \%$ ( $n$ $=40$ ) of the participants belonged to the age group of 2034 years and $21.6 \%(n=11)$ belonged to the age group of $\geq 35$ years. There were $33(64.7 \%)$ males and 18 (35.3\%) females. 25 (49\%) participants were married and 26 (51\%) were unmarried. The educational qualification of workers was: illiterate - 19 (37.3\%), primary - $3(5.9 \%)$, middle - 6 $(11.8 \%)$, secondary - 13 (25.5\%), and higher secondary - 10 (19.6\%). 66.7\% of the respondents had no past history of any disease, 3.9\% had accidental injury in industry, $7.8 \%$ had burning micturition, 3.9\% had breathlessness, 3.9\% had recurrent loose stool with vomiting, and $13.7 \%$ had taken TB treatment. 6 (11.8\%) participants had a family history of allergy and 45 (88.2\%) had no family history of allergy. Out of these, 2 had a history of allergic rhinitis, 2 had a history of asthma, and 2 had a history of skin allergy. $33(64.7 \%)$ study subjects were vegetarian, 6 (11.7\%) were consuming tobacco, and 7 (13.7\%) were consuming alcohol.

Table 1, shows the response of participants to the Respiratory Allergy Prediction test (RAP Questionnaire). 43.1\% had nasal symptoms that worsen in a dusty environment, $39.2 \%$ suffered from itchy/ red/ watery eyes during the year, $27.5 \%$ had a cough or shortness of breath, even during exercise, $23.5 \%$ had nasal/ ocular complaints that usually start or worsen during the spring, $23.5 \%$ had parents/ relatives suffering from rhinitis and/ or asthma, $15.7 \%$ experienced runny nose/ nasal obstruction/ nasal itching for many consecutive days, $15.7 \%$ had wheezing, $11.8 \%$ had nocturnal awakenings due to shortness of breath or cough, and $7.8 \%$ used nasal sprays frequently.

The association of the responses to RAP Questionnaire to age, gender, type of work, family history of allergy, and history of previous employment in the industry is shown in Table 2. The association of the independent variable "family history of allergy" was significant with one of the RAP questions "Do you have parents/ relatives suffering from rhinitis and/ or asthma?" ( $p$ value $=0.008$ ).

\section{Table I.Responses of Participants to RAP Questionnaire}

\begin{tabular}{|c|c|c|}
\hline RAP Questions & Number (n = 51) & Percentages \\
\hline Q1. Do you have parents/ relatives suffering from rhinitis and/ or asthma? & 12 & 23.5 \\
\hline Q2. Do you suffer from itchy/ red/ watery eyes during the year? & 20 & 39.2 \\
\hline Q3. Do you experience runny nose/ nasal obstruction/ nasal itching for many \\
consecutive days? & 8 & 15.7 \\
\hline Q4. Do your nasal/ ocular complaints usually start or worsen during the spring? & 23.5 \\
\hline Q5. Have you ever had wheezing? & 8 & 12.7 \\
\hline Q6. Did you ever have cough or shortness of breath, even during exercise? & 14 & 27.5 \\
\hline Q7. Do you have nocturnal awakenings due to shortness of breath or cough? & 6 & 11.8 \\
\hline Q8. Do you use nasal sprays frequently? & 4 & 2.8 \\
\hline Q9. Do you feel that your nasal symptoms worsen in dusty environments? & 22 & 43.1 \\
\hline
\end{tabular}

Table 2.Association of RAP Questionnaire Responses to Age, Gender, Type of Work, Family History of Allergy, and History of Previous Employment in Industry

\begin{tabular}{|c|c|c|c|c|c|c|c|c|c|}
\hline & $\begin{array}{c}\text { Q1 }(n= \\
12)\end{array}$ & Q2 $(n=20)$ & Q3 $(n=8)$ & $\mathrm{Q} 4(\mathrm{n}=12)$ & $\begin{array}{l}\text { Q5 (n } \\
=8)\end{array}$ & $\begin{array}{l}\text { Q6 (n } \\
=14)\end{array}$ & $\begin{array}{l}\text { Q7 (n } \\
=6)\end{array}$ & $\mathrm{Q} 8(n=4)$ & $Q 9(n=22)$ \\
\hline \multicolumn{10}{|c|}{ Age (years) } \\
\hline $20-34$ & 12 & 16 & 8 & 12 & 8 & 12 & 6 & 4 & 18 \\
\hline$\geq 35$ & 0 & 4 & 0 & 0 & 0 & 2 & 0 & 0 & 4 \\
\hline$P$ value & 0.38 & 0.82 & 0.10 & 0.03 & 0.10 & 0.43 & 0.17 & 0.27 & 0.60 \\
\hline \multicolumn{10}{|c|}{ Gender } \\
\hline Male $(n=33)$ & 8 & 12 & 4 & 10 & 4 & 8 & 6 & 4 & 12 \\
\hline
\end{tabular}




\begin{tabular}{|c|c|c|c|c|c|c|c|c|c|}
\hline Female $(n=18)$ & 4 & 8 & 4 & 2 & 4 & 6 & 0 & 0 & 10 \\
\hline$P$ value & 0.87 & 0.57 & 0.34 & 0.12 & 0.34 & 0.48 & 0.05 & 0.12 & 0.18 \\
\hline \multicolumn{10}{|c|}{ Marital status } \\
\hline Married $(n=25)$ & 4 & 8 & 6 & 4 & 4 & 6 & 2 & 0 & 12 \\
\hline $\begin{array}{l}\text { Unmarried }(n= \\
26)\end{array}$ & 8 & 12 & 2 & 8 & 4 & 8 & 4 & 4 & 10 \\
\hline$P$ value & 0.21 & 0.30 & 0.10 & 0.21 & 0.95 & 0.58 & 0.41 & 0.04 & 0.49 \\
\hline \multicolumn{10}{|l|}{ Type of work } \\
\hline Packing $(n=7)$ & 0 & 2 & 0 & 0 & 0 & 0 & 0 & 0 & 4 \\
\hline $\begin{array}{c}\text { Quality check ( } \mathrm{n} \\
=4 \text { ) }\end{array}$ & 2 & 2 & 4 & 0 & 0 & 2 & 0 & 0 & 0 \\
\hline Printing $(n=10)$ & 2 & 2 & 0 & 2 & 2 & 4 & 2 & 2 & 4 \\
\hline Moulding $(n=30)$ & 8 & 14 & 8 & 10 & 6 & 8 & 4 & 2 & 14 \\
\hline$P$ value & 0.26 & 0.42 & 0.08 & 0.16 & 0.45 & 0.21 & 0.53 & 0.38 & 0.28 \\
\hline \multicolumn{10}{|c|}{ Family history of allergy } \\
\hline Yes & 4 & 4 & 0 & 0 & 0 & 0 & 0 & 0 & 2 \\
\hline No & 8 & 16 & 8 & 12 & 8 & 14 & 6 & 4 & 20 \\
\hline$P$ value & 0.008 & 0.14 & 0.26 & 0.14 & 0.26 & 0.10 & 0.34 & 0.44 & 0.60 \\
\hline \multicolumn{10}{|c|}{ History of previous employment in industry } \\
\hline Yes & 8 & 10 & 8 & 6 & 8 & 8 & 6 & 2 & 12 \\
\hline No & 4 & 10 & 0 & 6 & 0 & 6 & 0 & 2 & 10 \\
\hline$P$ value & 0.27 & 0.73 & 0.004 & 0.81 & 0.004 & 0.71 & 0.01 & 0.90 & 0.84 \\
\hline
\end{tabular}

Table 3.Distribution of Skin Lesions on Different Parts of the Body

\begin{tabular}{|c|c|c|c|c|c|c|}
\hline $\begin{array}{c}\text { Types of Skin } \\
\text { Problems }\end{array}$ & Hands (n) & Arms, Forearms (n) & Lower Legs (n) & Trunk (n) & Head, Neck (n) & Total (\%) $\mathbf{n = 5 1}$ \\
\hline Itching & 8 & 4 & 0 & 0 & 4 & $16(31.4)$ \\
\hline Papules & 8 & 2 & 0 & 0 & 4 & $14(27.5)$ \\
\hline Blisters & 4 & 0 & 0 & 0 & 0 & $4(7.8)$ \\
\hline Oozing & 4 & 0 & 0 & 0 & 0 & $4(7.8)$ \\
\hline Dry/ scaly skin & 4 & 2 & 0 & 0 & 2 & $8(15.7)$ \\
\hline
\end{tabular}

Table 4.Association of Skin Lesions with Age, Type of work, and Family History of Allergy

\begin{tabular}{|c|c|c|c|c|c|c|}
\hline Variables & Itching $(\mathbf{n}=\mathbf{1 6})$ & Papules $(\mathbf{n}=\mathbf{1 4})$ & Blisters $(\mathbf{n}=\mathbf{4})$ & Oozing $(\mathbf{n}=\mathbf{4})$ & $\begin{array}{c}\text { Dry/ Scaly Skin } \\
(\mathbf{n}=10)\end{array}$ & Total (n= 51) \\
\hline \multicolumn{7}{|c|}{ Age (years) } \\
\hline $20-34$ & $14(87.2 \%)$ & $12(85.7 \%)$ & $4(100 \%)$ & $4(100 \%)$ & $8(80 \%)$ & $40(78.4 \%)$ \\
\hline$\geq 35$ & $2(12.5 \%)$ & $2(14.3 \%)$ & $0(0 \%)$ & $0(0 \%)$ & $2(20 \%)$ & $11(21.6 \%)$ \\
\hline P value & 0.28 & 0.43 & 0.27 & 0.27 & 0.89 & \\
\hline \multicolumn{7}{|c|}{ Type of work } \\
\hline Packaging & $0(0 \%)$ & $0(0 \%)$ & $0(0 \%)$ & $0(0 \%)$ & $0(0 \%)$ & $7(13.7 \%)$ \\
\hline Quality check & $0(0 \%)$ & $0(0 \%)$ & $0(0 \%)$ & $0(0 \%)$ & $0(0 \%)$ & $4(7.8 \%)$ \\
\hline Printing & $6(37.5 \%)$ & $6(42.9 \%)$ & $2(50 \%)$ & $2(50 \%)$ & $2(20 \%)$ & $10(19.6 \%)$ \\
\hline Moulding & $10(62.5 \%)$ & $8(57.1 \%)$ & $2(50 \%)$ & $2(50 \%)$ & $8(80 \%)$ & $30(58.8 \%)$ \\
\hline
\end{tabular}




\begin{tabular}{|c|c|c|c|c|c|c|}
\hline P value & 0.03 & 0.02 & 0.38 & 0.38 & 0.30 & \\
\hline \multicolumn{7}{|c|}{ Family history of allergy } \\
\hline Yes & $0(0 \%)$ & $0(0 \%)$ & $0(0 \%)$ & $0(0 \%)$ & $0(0 \%)$ & $6(11.8 \%)$ \\
\hline No & $16(100 \%)$ & $14(100 \%)$ & $4(100 \%)$ & $4(100 \%)$ & $10(100 \%)$ & $45(88.2 \%)$ \\
\hline P value & 0.07 & 0.10 & 0.44 & 0.44 & 0.19 & \\
\hline
\end{tabular}

Table 3, shows the distribution of skin lesions on different parts of the body. Hands were the most commonly affected with all 5 types of skin problems. Blisters and oozing were found only on hands. No lesions were found in the lower legs and trunk. Besides hands, itching, papules, and dry/ scaly skin were found only on the head/ neck and arms/ forearms. A total of $31.4 \%$ of the participants had itching, $27.5 \%$ had papules, $7.8 \%$ had blisters, $7.8 \%$ had oozing, and $15.7 \%$ had dry/ scaly skin.

Persons involved in packaging and quality check did not have any skin problem while those involved in printing and moulding of shoes had one or the other skin problem. Skin problems like itching and papules were significantly associated with printing and moulding of shoes. $11.8 \%(n=$ 6) of the participants had a family history of allergy but none of these 6 participants had skin lesions. The association of the age of participants and family history of allergy with skin problems was non-significant. This is shown in Table 4.

\section{Discussion}

This study showed the relationship between occupational exposures associated with work in the footwear industry and symptoms of rhinitis along with skin lesions. In the present study, workers involved in printing and moulding responded positively to one or the other problem mentioned in the RAP questionnaire while among the workers involved in packaging, only 2-4 respondents reported worsening of nasal symptoms in a dusty environment (Q9) and itchy/ $\mathrm{red} /$ watery eyes during the year (Q9). Among the workers involved in quality check, only 2-4 respondents suffered from red/itchy eyes during the year (Q2), experienced runny nose/ nasal obstruction for many consecutive days (Q3), or had cough or shortness of breath even during exercise (Q6). The results reveal that workers in the shoe industry show allergic symptoms irrespective of the type of work but those involved in moulding and printing activities are affected the most. Gangopadhyay $S^{8}$ in his study done in Kolkata found that workers involved in various types of activities apart from stitching had a significantly lower peak flow rate than their predicted Peak Expiratory Flow Rate (PEFR) value. The inhalation of leather dust and toxic adhesives during work causes the deposition of small particles along the lining of alveoli that decreases the ventilation-perfusion ratio and thus reduces lung capacity and PEFR value.

In the present study, all types of skin lesions such as itching, papules, blisters, oozing, and dry/ scaly skin were found in the workers employed in printing and moulding of shoes. Also, all the lesions were found in the upper part of the body with the involvement of hands, arms, forearms, and head/ neck in some cases. In a study done by Febriana SA in Indonesia, ${ }^{9}$ it was found that skin lesion was maximum in those involved in upper sole preparation and sewing. In his/ her study, occupational skin diseases were diagnosed in $29 \%$ of the workers by dermatologists and $7.6 \%$ had Occupational Contact Dermatitis (OCD). $4.9 \%$ of the participants had Occupational Irritant Contact Dermatitis (OICD). In preparing the upper sole and printing process, there are direct skin exposures to a wide variety of solvents and organic chemicals. The high prevalence of skin lesions may have been caused by heat exposure from heat-generating machines leading to a high ambient temperature $\left(38-40^{\circ} \mathrm{C}\right)$ and humidity $(80 \%)$.

\section{Conclusion}

Shoe-making is a process that involves exposure to a number of hazardous organic and inorganic compounds along with toxic fumes that may lead to allergic rhinitis as well as skin allergies in the form of skin lesions especially among those involved in printing and moulding of shoes. It may be concluded that the workers who are engaged in various footwear manufacturing activities should adopt workplace protection by adopting preventive measures like wearing gloves and masks.

\section{Conflict of Interest: None declared}

Source of Funding: This research did not receive any specific grant from funding agencies in the public, commercial, or not-for-profit sectors.

\section{References}

1. Szubert Z, Wilczynska U, Sobala W. Health risk among workers employed in rubber footwear plant. Med Pr. 2001;52:409. [PubMed] [Google Scholar]

2. Zuskin E, Mustajbegovic J, Doko-Jeliniae J, Kern J, Bradiae V. Respiratory symptoms, diseases and ventilatory function in shoe industry workers. Arh Hig Rada Toxic. 1996;47: 189-97. [PubMed] [Google Scholar]

3. Paggiaro P, Lastrucci L, Di Pede C, Bacci E, Rossi O, Talini D. Respiratory pathology caused by exposure to solvents in the shoe industry: Description of 3 clinical cases. G Ital Med Lav.1985;7:149-52. [PubMed] [Google 
Scholar]

4. Taylor JS, Erkek E, Podmore P. Shoes. In: Frosch PJ, Menné T, Lepoittevin JP, editors. Contact Dermatitis. 4th ed. Berlin, Heidelberg: Springer Publising; 2006.

5. Geier J. Leather and Shoes. In: Kanerva L, Wahlberg JE, Elsner P, Maibach HI, editors. Handbook of Occupational Dermatology. Berlin, Heidelberg: Springer Publising; 2000. [Google Scholar]

6. Mancuso G, Reggiani M, Berdondini RM. Occupational dermatitis in shoemakers. Contact Dermatitis. 1996;34(1):17-22. [PubMed] [Google Scholar]

7. Galimberti M, Passalacqua G, Incorvaia C, Castella V, Costantino MT, Cucchi B, Gangemi S, Nardi G, Raviolo P, Scichilone N, Sciolla N, Bettonselli G, Landi M, Ridolo E, Buttafava S, Puccinelli P, Canonica GW, Frati F. Catching allergy by a simple questionnaire. World Allergy Organ J. 2015;8:16. [PubMed] [Google Scholar]

8. Gangopadhyay S, Ara T, Dev S, Ghoshal G, Das T. An occupational health study of the footwear manufacturing workers of Kolkata, India. Ethno Med. 2011;5(1):11-15. [Google Scholar]

9. Febriana SA, Soebono H, Coenraad PJ. Occupational skin hazards and prevalence of occupational skin diseases in shoe manufacturing workers in Indonesia. Int Arch Occup Environ Health. 2014;87(2):185-94. [PubMed] [Google Scholar] 